\section{GC}

Revista Nacional de

Gerenciamento de Cidades

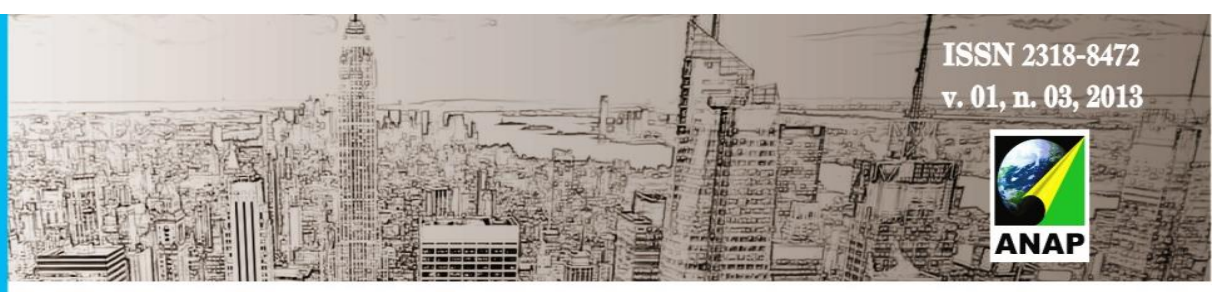

\title{
IMPLANTAÇÃO DE SISTEMAS DE GERENCIAMENTO E FISCALIZAÇÃO DE OBRAS NAS CIDADES. ESTUDO DE CASO: CONDOMINIOS HORIZONTAIS FECHADOS
}

\author{
Elaine Saraiva Calderari ${ }^{1}$
}

Anderson Assunção Batista²

Francesco Simões Petronzio ${ }^{3}$

RESUMO: Este trabalho visa o desenvolvimento de um sistema, como um produto diferenciado e inovador para o gerenciamento de projetos e fiscalização de obras em condomínios horizontais fechados, por meio do uso de tecnologias de ponta, em computadores ou equipamentos com internet móvel (como tablets e smartphones). $\mathrm{O}$ projeto proposto é embrionário para em futuro ser um sistema capaz de atender uma cidade completa, no entanto neste momento a ideia é proporcionar ao setor da construção civil, na implantação de condomínios horizontais fechados, uma solução para melhoria e

\footnotetext{
${ }^{1}$ Doutoranda em Arquitetura e Urbanismo na Universidade de São Paulo, Mestre em Engenharia Urbana na Universidade Federal de Uberlândia, Arquiteta e Urbanista na Universidade Federal de Uberlândia. Desempenha função de Coordenadora de projetos na Divisão de projetos da Universidade Federal de Uberlândia. Email: elainesc.ufu@gmail.com.

${ }_{2}^{2}$ Arquiteto e Urbanista pela Universidade Estadual de Goiás, Pós-Graduando em Gestão e Tecnologia na Construção Civil na Universidade Federal de Lavras. Desempenha função de Diretor de Processos no escritório AE arquitetura e Consultoria Ltda. Email: aearquitetos@gmail.com

${ }^{3}$ Analista e Desenvolvedor de Sistemas pela Universidade -UNIPAC- Campus Uberlândia.
} 

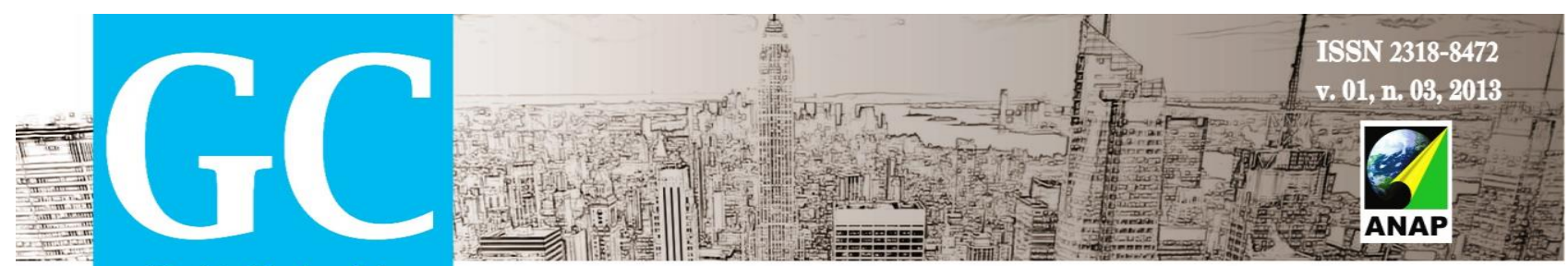

Revista Nacional de

Gerenciamento de Cidades

otimização nos serviços prestados em aprovação de projetos e fiscalização de obras, com a elaboração de avaliações, relatórios, planilhas e material fotográfico, de forma sistematizada e integrada, fornecendo dados e informações facilitadas e atualizadas, principalmente sobre a situação de todos os projetos em análise e as obras em andamento, aos proprietários, administradores, incorporadores e profissionais que atuam em condomínios horizontais fechados, estabelecendo um rigoroso controle e cumprimento das restrições urbanísticas.

\section{INTRODUÇÃO}

As transformações urbanas levaram a necessidade de elaboração de legislação que regulasse a ocupação dos espaços urbanos de forma a possibilitar o crescimento minimamente ordenado das cidades. A política de produção e organização do espaço urbano é estabelecida por meio do zoneamento urbano estabelecido pelos Planos Diretores, Leis e Códigos de uso e ocupação de cada cidade e baseados nas diretrizes propostas pelo Estatuto da Cidade (Lei no.10.257/01).

Sendo o uso do zoneamento a ferramenta que estabelece diretrizes diferenciadas para o uso e a ocupação do solo, especialmente as normas urbanísticas. Essas normas possuem o papel de regulador da ação dos agentes imobiliários produtores, apropriadores e consumidores do espaço urbano, de forma a assegurar a qualidade dos empreendimentos pelos níveis de infraestrutura e serviços urbanos presentes e ausentes, e pelos níveis de conforto e qualidade ambiental e estética.

As cidades condicionam e controlam a forma urbana, por meio dos índices e parâmetros urbanísticos estabelecidos por códigos ou regimentos que direta ou indiretamente, interfiram na configuração dos edifícios e seus espaços adjacentes. Constituem-se, via de regra, da reunião de normativas relacionadas com as edificações de uma maneira geral, mas também de outras regulamentações oriundas de áreas de conhecimento afins. Normas de conduta higiênica decoro público, padrões edilícios, 

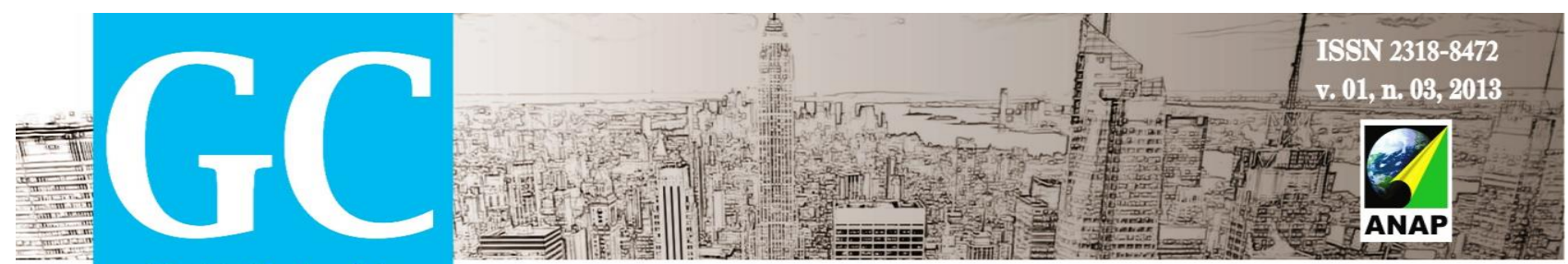

Revista Nacional de

Gerenciamento de Cidades

alinhamentos, competências, aspectos ambientais, culturais e de planejamento urbano se aglutinam na forma de conjuntos de leis historicamente definidos.

Entende-se que o conceito de forma urbana como o produto das relações estabelecidas pelo homem, e como um dos instrumentos de controle para obter condições de conforto e salubridade do espaço citadino. A forma urbana deve ser projetada especialmente para proporcionar um entorno adequado para a interação social e a vida comunitária, para apoiar, fomentar e nutrir os laços sociais e para favorecer e estimular a interação entre as pessoas (RUANO, 2000). Essas expectativas, devidamente organizadas, definem as funções dos espaços urbanos e, consequentemente, as dimensões sobre as quais a arquitetura deve se dedicar para a estruturação de seu campo disciplinar.

Os dispositivos procuram controlar o crescimento da cidade porque definem, zona a zona, com o número máximo de pavimentos e/ou a altura total da edificação; o coeficiente de Aproveitamento máximo do lote $(\mathrm{CA})$, que representa a área máxima possível de ser construída dividida pela área do lote; a taxa de ocupação máxima permitida para o lote; os afastamentos frontal, laterais e de fundos; o tamanho mínimo do lote; a taxa de permeabilidade do solo, o gabarito máximo, entre outros.

a)

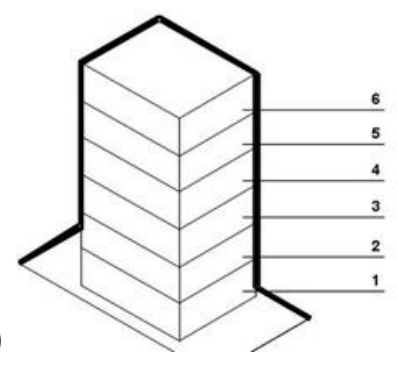

c)

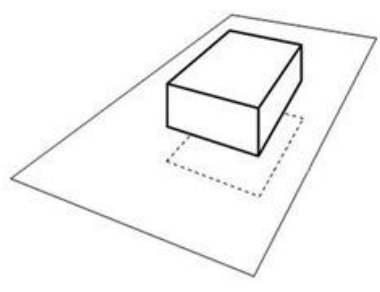

b)

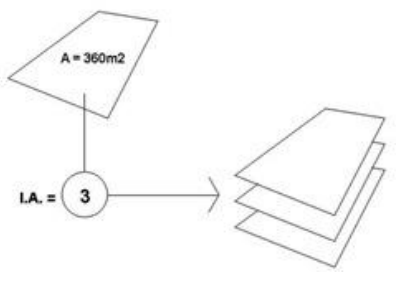

d)

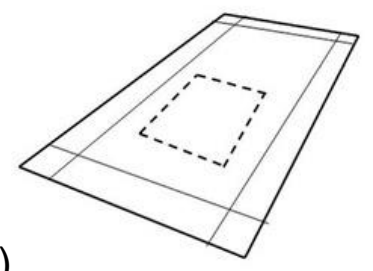

FIGURA 01: a) Número máximo de pavimentos b) Coeficiente ou índice de aproveitamento.

c) Taxa de ocupação. d) Afastamentos. FONTE: http:// www.urbanidades.arq.br. Acessado em março/2013. 


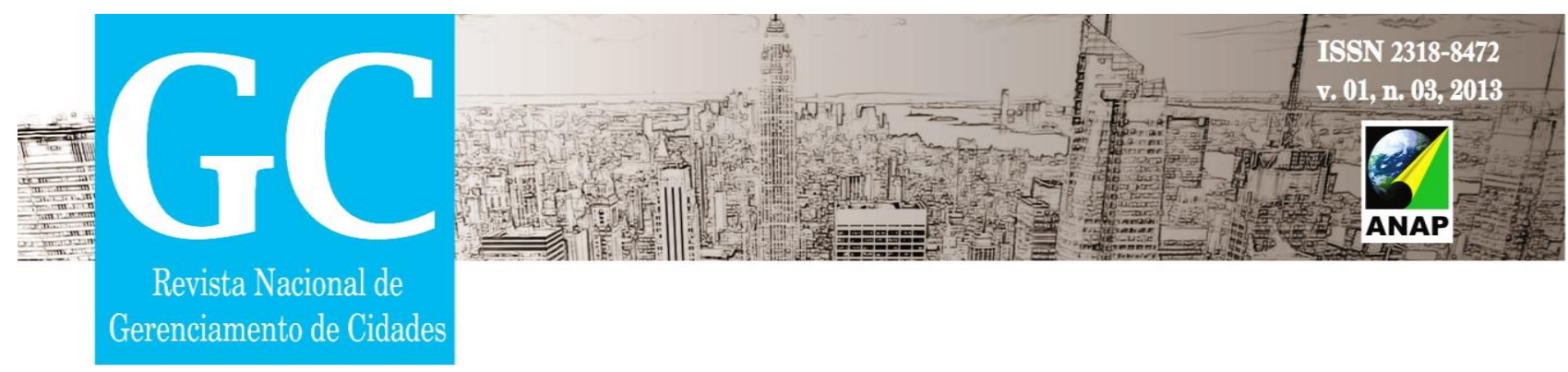

Entende-se que a função dos profissionais de arquitetura e engenharia civil, é de garantir o cumprimento dessas normas, a fim de consolidarmos cidades atrativas, equilibradas e ordenadas, em harmonia com a disposição de recursos e a construção da equidade.

Diante dessa situação, o desenvolvimento urbano compreende a morfologia urbana a partir da lógica evolutiva e estruturada para o crescimento orgânico, questionando e propondo modelos urbanos que correspondam às novas necessidades ambientais e de qualidade sustentável, por meio de novas formas de apropriação do espaço, condizentes com as necessidades emergenciais apresentadas à sociedade global.

No entanto, em muitas cidades o controle dos índices urbanísticos, é realizado apenas na aprovação do projeto, sendo que durante a obra, as características são totalmente alteradas, principalmente pela fiscalização inadequada ou mesmo pela falta da própria fiscalização.

Sabe-se que a fiscalização em grande maioria, é realizada de forma manual, onde o técnico por meio de visitações e anotações em pranchetas, verifica a situação atual da obra e depois remetem ao supervisor, e posteriormente que se inicia um processo de confirmação de informações, solicitação ou não de paralisação de obra e punições. Além disso, devido aos grandes números de obras a ser visitado, o controle ainda é realizado apenas uma ou duas vezes em cada obra durante toda a execução, tornando-se totalmente ineficiente para um controle adequado.

No mercado não existem sistemas operacionais diretamente elaborados para esse mercado e função. Na grande maioria, são softwares com funções gerais, não possuem campos flexíveis, não são adaptáveis a novas situações e não atendem diretamente os profissionais deste setor.

Assim, o projeto proposto é embrionário para em futuro ser um sistema capaz de atender uma cidade completa, no entanto devido às dimensões e complexidades significativas de uma cidade, como também o livre acesso em alguns empreendimentos, é 


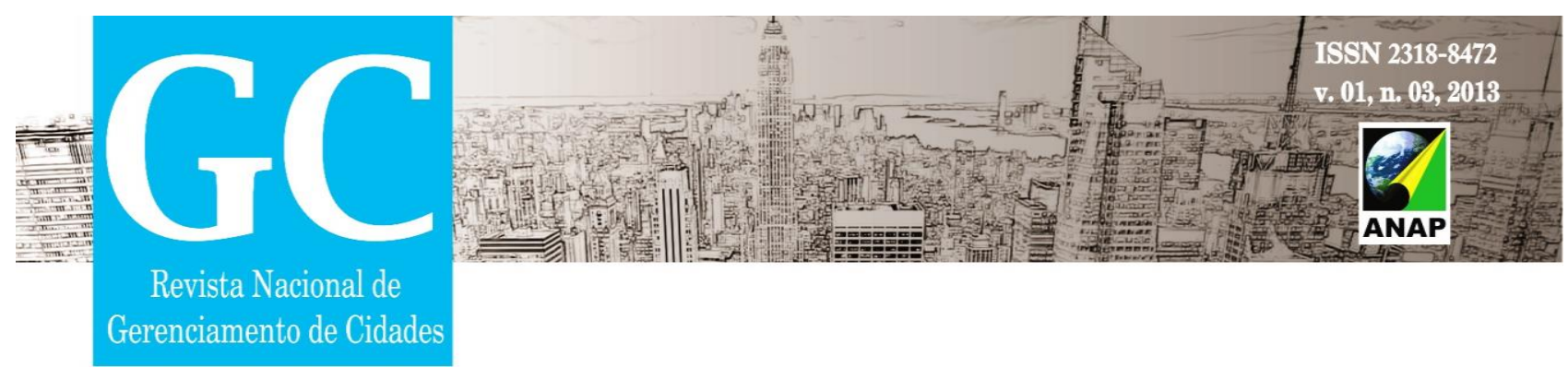

proposto como modelo, à aplicação inicial do sistema em condomínios fechados horizontais ${ }^{4}$. Já que entende que essas tipologias de condomínios são como pequenos núcleos urbanos, ou seja, pequenas cidades dentro de grandes cidades e também se configura como modalidade habitacional em constante crescimento, e oferecem características, potencialidades e problemáticas semelhantes.

Além disso, os condomínios possuem legislações próprias, condicionadas a legislação municipal, com critérios mais rígidos e normativos diferenciados a fim de garantir um desenvolvimento urbano planejado e, portanto são modelos ideias, em um escala acessível de ser estruturado no modelo de gerenciamento e fiscalização, a fim de fazer estabelecer parâmetros para a realização de testes capazes de nos fornecer resultados positivos ou negativos dentro de um período de significativo para a maturação do projeto.

\section{OBJETIVOS}

O objetivo geral deste trabalho é elaboração de um sistema de controle e gerenciamento de projetos e fiscalização de obras em condomínios horizontais fechados, em um modelo integrado entre obra, fiscalização, administração e proprietários, por meio do uso de tecnologias de ponta, em computadores e equipamentos com internet móvel (como tablets e smartphones).

A ideia é proporcionar ao setor da construção civil, na implantação de condomínios horizontais fechados, uma solução para melhoria e otimização nos serviços prestados em aprovação de projetos e fiscalização de obras, com a elaboração de avaliações, relatórios, planilhas e material fotográfico, de forma sistematizada e integrada,

\footnotetext{
${ }^{4}$ A denominação de condomínios fechados é utilizada para designar os empreendimentos imobiliários que, sem promover um parcelamento formal, dividem uma gleba em vários terrenos, que passam a ser alienados como unidades autônomas. O regime jurídico adotado pode ser o do condomínio em edificações ou o do condomínio ordinário. Fenômeno semelhante ao dos condomínios horizontais é o dos loteamentos fechados, em que há um parcelamento formal do solo, mas uma associação de moradores assume a administração as áreas publicas (vias, áreas verdes, lazer e recreação, institucional, outras) ao loteamento.
} 


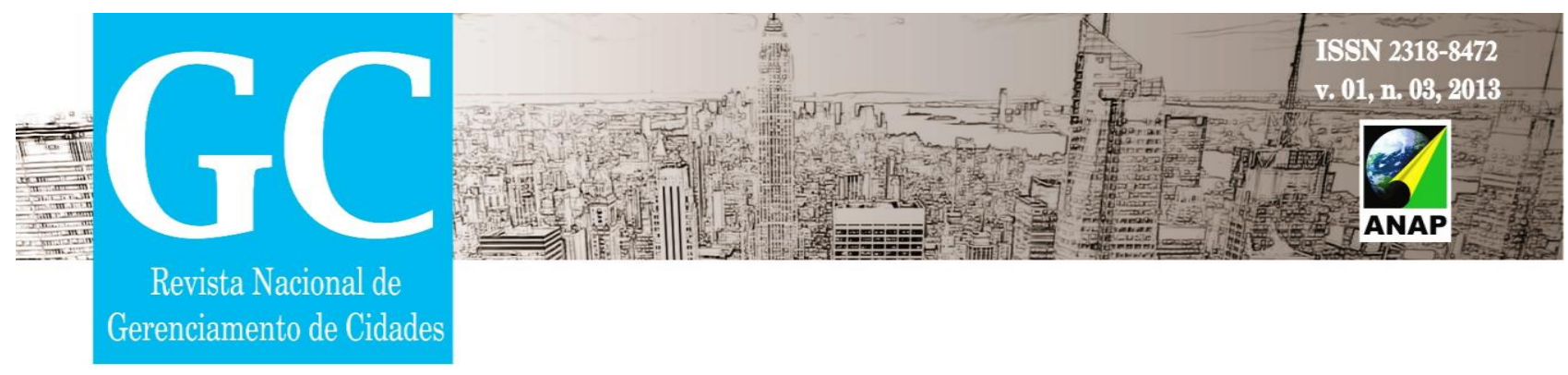

fornecendo dados e informações facilitadas e atualizadas, principalmente sobre a situação de todos os projetos em análise e as obras em andamento, aos proprietários, administradores, incorporadores e profissionais que atuam em condomínios horizontais fechados, estabelecendo um rigoroso controle e cumprimento das restrições urbanísticas.

\section{JUSTIFICATIVA}

O Ministério da Fazenda publicou em março de 2013 um relatório intitulado "Economia Brasileira em Perspectiva", que mostra que a economia do Brasil está fortalecida e aponta para o crescimento em ritmo forte, cerca de 5\% em média, até 2014. As bases desta expansão são o mercado interno e os investimentos, principalmente em infraestrutura e construção civil.

Essa situação promoveu ao mercado brasileiro da construção civil um crescimento vertiginoso, porém, sem estar preparado, apesar de previsto. Nos últimos 12 meses, a alta registrada especificamente no setor da construção civil foi de $6,8 \%$, variando, em média, $1,5 \%$ em cada mês de acordo com o SINDUSCON (Sindicato da Construção Civil).

Além disso, estima-se que em 2002, quatro milhões de pessoas já viviam em condomínios fechados, ou seja, quase $2,5 \%$ da população total. Assim, verifica-se que, atualmente, os condomínios fechados representam uma grande fatia do mercado imobiliário mundial, com grande aceitação por parte dos usuários-consumidores, que os procuram cada vez mais. Não são mais exclusividades das classes altas e nem estão localizados apenas em grandes cidades, sendo construídos para classes de menor poder aquisitivo e em diversos países, principalmente no Brasil.

Neste contexto, o trabalho proposto pretende atender diretamente ao mercado da construção civil, introduzindo o uso de tecnologias e da informatização, em dos setores crescentes no mercado imobiliário e atualmente é apontado como um produto altamente rentável dentro da construção, a expansão dos condomínios horizontais fechados. 


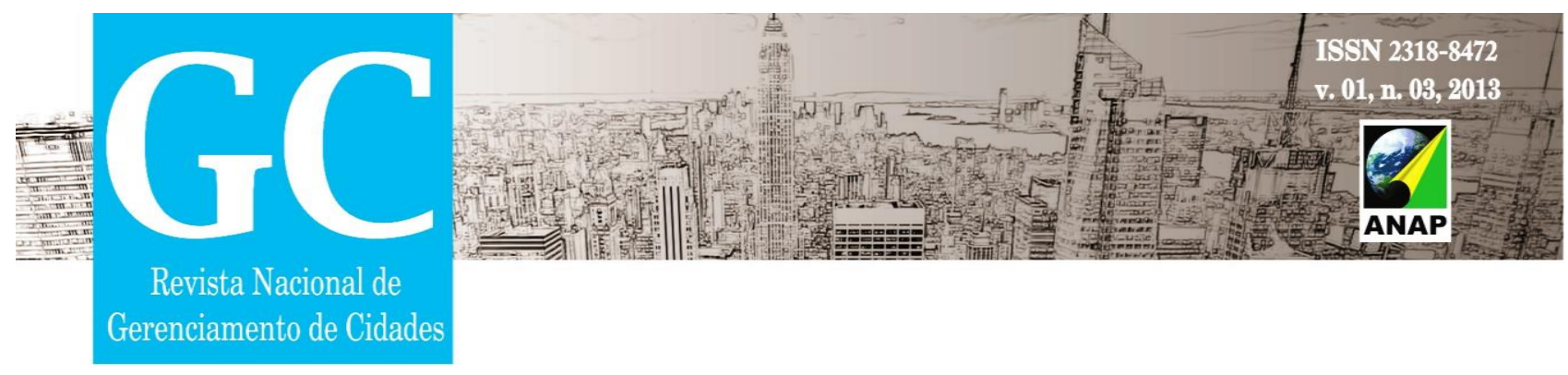

A utilização de tecnologias já faz parte do cotidiano de praticamente todas as pessoas. Mesmo aquelas que pensam que nunca utilizaram um software, Internet, ou um computador, na verdade já se beneficiam dos avanços da informática e também poderão sofrer as consequências de um erro, defeito ou falha de um software. Os exemplos estão por toda parte: nos bancos, nos supermercados, nos transportes coletivos, em automóveis, entre outros, onde o uso de cartões de pagamento, de senhas de acesso, de vale-transporte, de aparelhos celulares são no fundo formas de se utilizar ou de interagir com um programa de computador que está por trás do que se está pretendendo pagar, comprar, verificar, etc.

Hoje em dia, com o aquecimento da economia brasileira, a construção civil encontra-se em um processo acelerado de crescimento. Os profissionais dessa área desenvolvem seus trabalhos em níveis elevados seja em quantidades de projetos/obras e/ou proporções (diversas escalas), e precisam atender com muita qualidade e em menos tempo.

Tão situação apenas é alcançada, quando existe o investimento no uso de novas tecnologias, como os softwares que tem como princípios básicos de funcionamento a integração, ou seja, a capacidade do software de derivar, a partir de um fato novo, todas as decorrências o que acarreta em redução de trabalho, velocidade e segurança; e a parametrização que significa informar ao software como são as políticas, normas e processos do serviço ofertado objetivando adequar o software às necessidades atuais da empresa e permitir a sua evolução futura.

Assim, o sistema proposto busca promover um modelo de gestão capaz de estabelecer um rigoroso controle no processo de aprovação e fiscalização das obras dentro dos condomínios, com um sistema capaz de produzir modelos de forma construída, artifício através do qual é possível averiguar os efeitos da aplicação dos índices urbanísticos estabelecidos em cada condomínio, mensurar seus resultados positivos e/ou negativos e verificar os impactos morfológicos, e inclusive ambientais promovidos antes, durante e depois de cada obra e poderá ser acessado online por todos os envolvidos, além de ser uma ferramenta de organização e armazenamento de dados. 

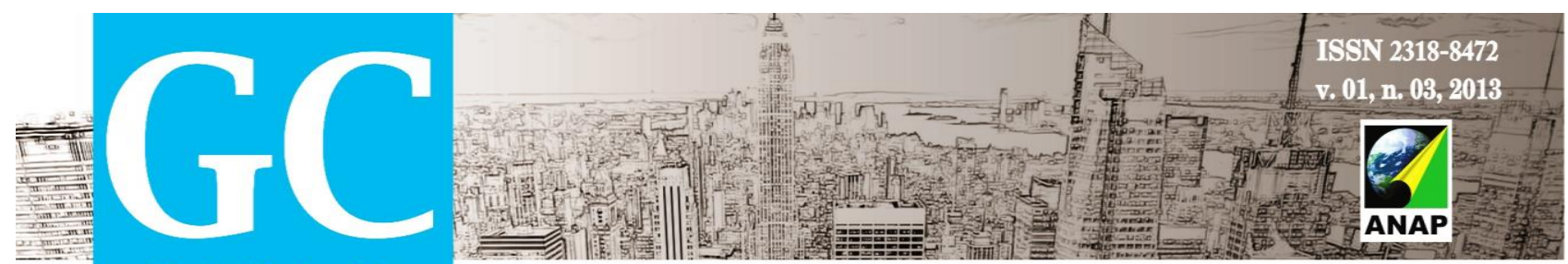

Revista Nacional de

Gerenciamento de Cidades

Com a implantação do sistema, os condomínios serão capazes de estabelecer os seguintes padrões:

- Padrão: estabelecer um padrão de análise e fiscalização de todos os projetos e obras em condomínios, podendo ser o mesmo ou condomínios diferentes, sendo a empresa capaz de manipular e analisar dados com metodologia e critérios homogêneos, independentes do profissional;

- Cumprimento das normas urbanísticas: estabelecer critérios de análise e fiscalização para o cumprimento de todas as normas estabelecidas em cada condomínio. Assim como a incorporação facilitada de novas normas ou a retirada de antigas;

- Otimização de tempo: estabelecer critérios que são capazes de otimizar o tempo de execução das tarefas, e estabelecendo resultados estatísticos comparativos de forma facilitada;

- Controle na execução e prazos: estabelecer um controle rigoroso no cumprimento de prazos de execução tanto na análise dos projetos, como na fiscalização de obras. Como também, monitorar os prazos de advertências, paralisações, punições ou suspensões de obra;

- Comunicação: estabelecer um sistema de comunição online entre os envolvidos (administração, fiscalização e proprietários) de forma rápida e fácil, por meio de computadores, tablets, smartphone, entre outros;

- Organização de informações e formação de banco de dados: estabelecer um sistema de organização sistematizada do material coletado no local (dados, planilhas, fotos, informações em geral) e com consulta online, tanto pela administração, como pelos proprietários dos condomínios, com acesso facilitado de cada obra. Sendo que o mesmo ficará registrado, formando um banco de dados para futuras consultas formando um histórico de cada obra; 

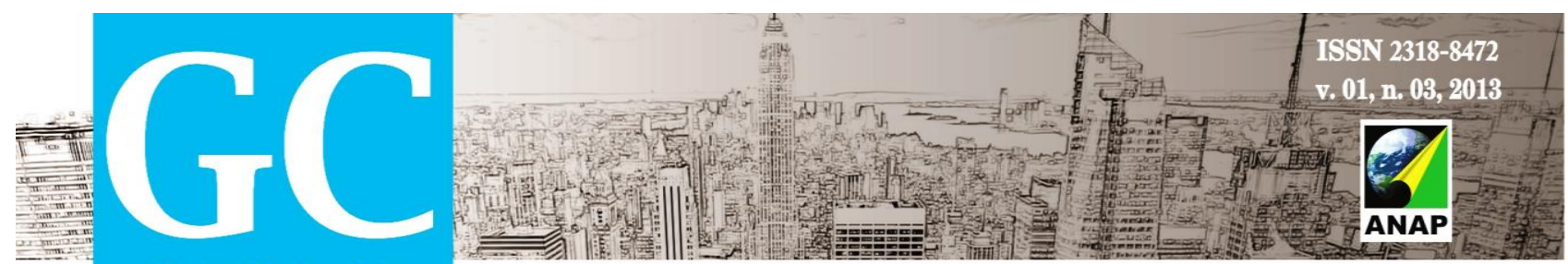

Revista Nacional de

Gerenciamento de Cidades

- Análises construtivas e ambientais: estabelecer relatórios, gráficos, e sistematizações capazes de avaliarem e armazenar situações inadequadas, sejam no caráter construtivo e/ou ambiental, a ponto ser identificando anteriormente a execução; e,

- Avaliação: estabelecer análises constantes sobre o serviço, para melhoria e aperfeiçoamento tanto do sistema, como do serviço prestado pela empresa.

\section{METODOLOGIA}

A metodologia a ser adotada na elaboração do projeto foi estruturada em 4 (quatro) fases bem definidas: Coleta, Concepção, Desenvolvimento e Detalhamento:

a) COLETA é a fase de coleta de todas as informações e documentações necessárias para a realização do trabalho, como também análise dos produtos existentes e escolha de um sistema de programação adequado. As informações foram organizadas e agrupadas, respeitando a metodologia de execução das tarefas e fazendo com que sejam facilmente assimiladas por todos da equipe, garantindo produtividade e qualidade e evitando assim desperdício de tempo. Nessa etapa foi possível identificar os principais conflitos, limites, potencialidades e definição das diretrizes a serem adotadas;

b) CONCEPÇÃO OU "BRIENFING" é apresentação do sistema preliminar. Neste momento, foram realizadas várias reuniões entre os profissionais da equipe técnica, para ajustes e adaptações a serem realizadas e posteriormente consultadas e/ou testadas em alguns condomínios, e analisados os resultados positivos e negativos;

c) DESENVOLVIMENTO: é o desenvolvimento completo do sistema, com todos os itens testados e verificados suas necessidades e potencialidades. Nessa fase, será incorporado o design do sistema, ou seja, a programação visual 

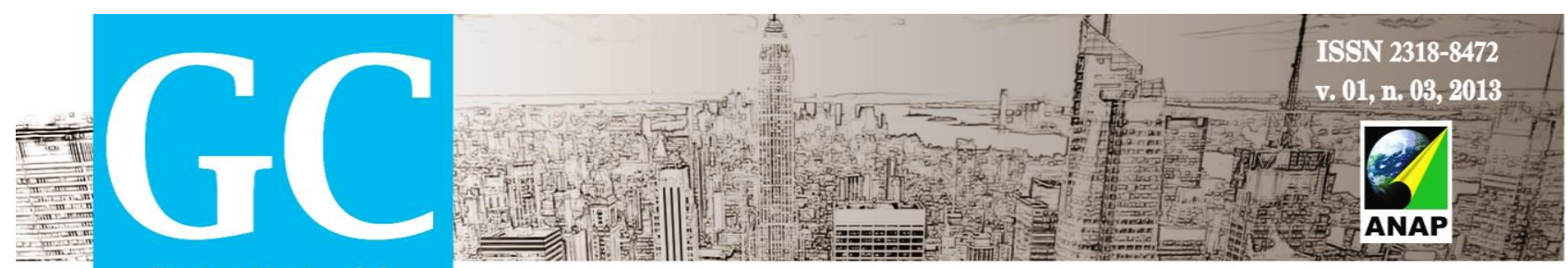

Revista Nacional de

Gerenciamento de Cidades

proposto para o sistema, trabalhando todas as inserções necessárias tanto funcionais como estéticas; $\mathrm{e}$,

d) DETALHAMENTO: é a fase de finalização e ajustes. Nesta etapa o sistema já estará funcionando em sua plenitude, e será colocado para ser utilizada nos condomínios, já como ferramenta de prestação de serviços.

Como técnica para execução do sistema, foi previsto um sistema online, programado dentro do próprio website, sendo acessado diretamente por meio de computadores, com chaves de proteção de dados, permitindo um acesso facilitado e a inserção de dados/informações por equipamentos com internet móvel (como tablets e smartphones). Para o desenvolvimento do material foram utilizados equipamentos com configurações mínimas:

Processador de núcleo único ou de múltiplos núcleos Intel® Pentium $\circledast$, Xeon $\circledast$, ou i-Series ou o $A M D \circledast$ equivalente com tecnologia SSE2. É recomendada a maior taxa de velocidade de CPU possível. Memória mínima: 6 GB RAM.

Para o desenvolvimento do sistema foram utilizadas as linguagens ASP, jquery , javascript, html, CSS. Além disso, também foram utilizados os softwares AutoCAD e Revit Architecture, da empresa Autodesk para a formatação das plantas indicativas de cada condomínio e o AdobePhotoshop para a elaboração da programação visual.

A equipe foi composta por um Coordenador (Arquiteto/Urbanista) e três profissionais (1 programador de sistemas, 1 estagiário de Engenharia Civil e 1 arquiteto/urbanista) foram diretamente envolvidos na sistematização do projeto, para testarem e analisarem os resultados do sistema no local de fiscalização, fornecendo informações constantes, para aprimoramento e melhorias do sistema.

Para os profissionais envolvidos foram definidas as funções apresentadas e cumpridas por cada participante e discutidas em equipe, onde as funções foram manipuladas e gerenciadas pelo coordenador do projeto, apontando as características de cada fase de execução do projeto por meio da análise e acompanhamento do cronograma 

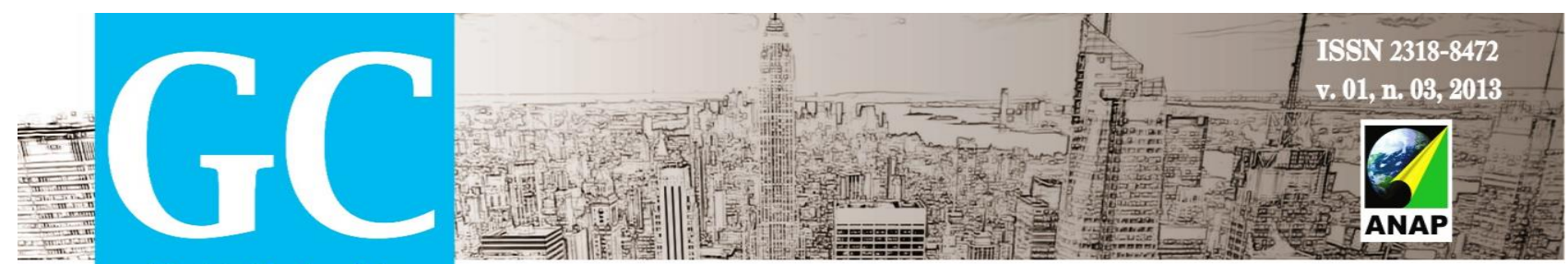

Revista Nacional de

Gerenciamento de Cidades

proposto e as necessidades de reuniões e encontros da equipe técnica completa, formando um único processo, como:

a. Integração - coordenação dos elementos derivados dos processos de escolha dos recursos a serem utilizados e decisões sobre gerenciamento de expectativas, equilíbrio entre conflitos, potenciais e objetivos, além da compatibilização entre todos os projetos;

b. Definição de Escopo - definição de todos os ciclos que percorrerão o projeto, desde a fase de elaboração até a entrega do produto final;

c. Definição de Tempo - controle de prazos;

d. Definição de Custo - orçamento para a realização do projeto;

e. Definição de Qualidade - esforço para obter a satisfação dos clientes;

f. Definição de Recursos Humanos - utilização das pessoas de uma melhor forma, de acordo com suas capacitações e funções desempenhadas;

g. Definição de Comunicações - geração, coleta e armazenamento de informações sobre o projeto, além dos comunicados de reuniões e encontros; e,

h. Definição de Riscos - análise dos perigos que podem ocorrer durante as realizações dos processos.

\section{DESENVOLVIMENTO}

Durante o desenvolvimento do sistema, as atividades chaves foram:

- Sistematização do software, que consta da concepção geral do programa, no desenvolvimento do padrão e da linguagem a ser utilizada e nos parâmetros a serem inseridos e manipulados;

- Elaboração de modelos virtuais dos condomínios, para o desenvolvimento em três dimensões da estrutura física dos condomínios, indicando os lotes vagos, construídos e a construir. Essa etapa é importante para garantir um acesso rápido 


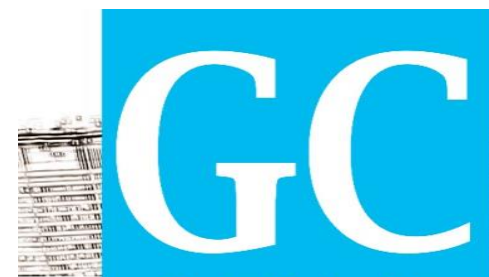

Revista Nacional de

Gerenciamento de Cidades

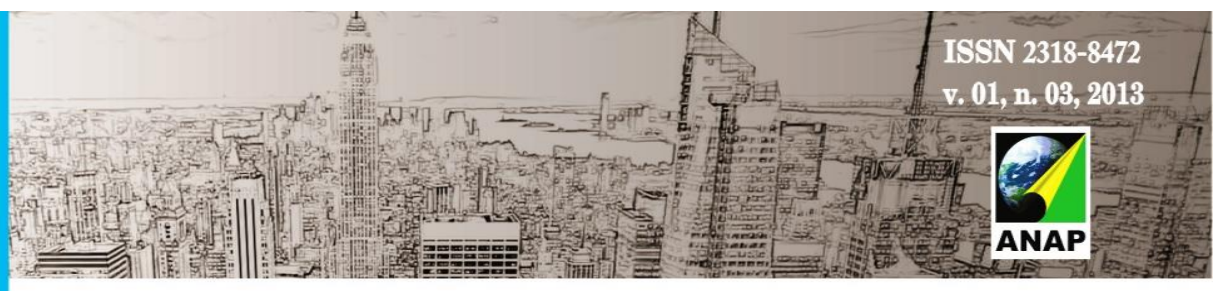

e facilitado às informações desejados em cada construção, além de garantir um banco de dados, informando as informações que ainda estão pendentes; e,

- Elaboração da programação visual, que consta na elaboração de um modelo contemporâneo e atrativo. Além disso, entende-se que o trabalho no design do software é importante para garantir a aceitabilidade do produto com 0 posicionamento correto de dados e informações e auxiliar na manipulação facilitada aos comandos promovendo uma interação com o cliente.

Para isso, foram utilizados 5 (cinco) condomínios horizontais na cidade de Uberlândia, no Estado de Minas Gerais (Figura 02), onde a empresa AE Arquitetura e Consultoria Ltda fornece essa tipologia de prestação de serviços, para a liberação e execução de testes do sistema.

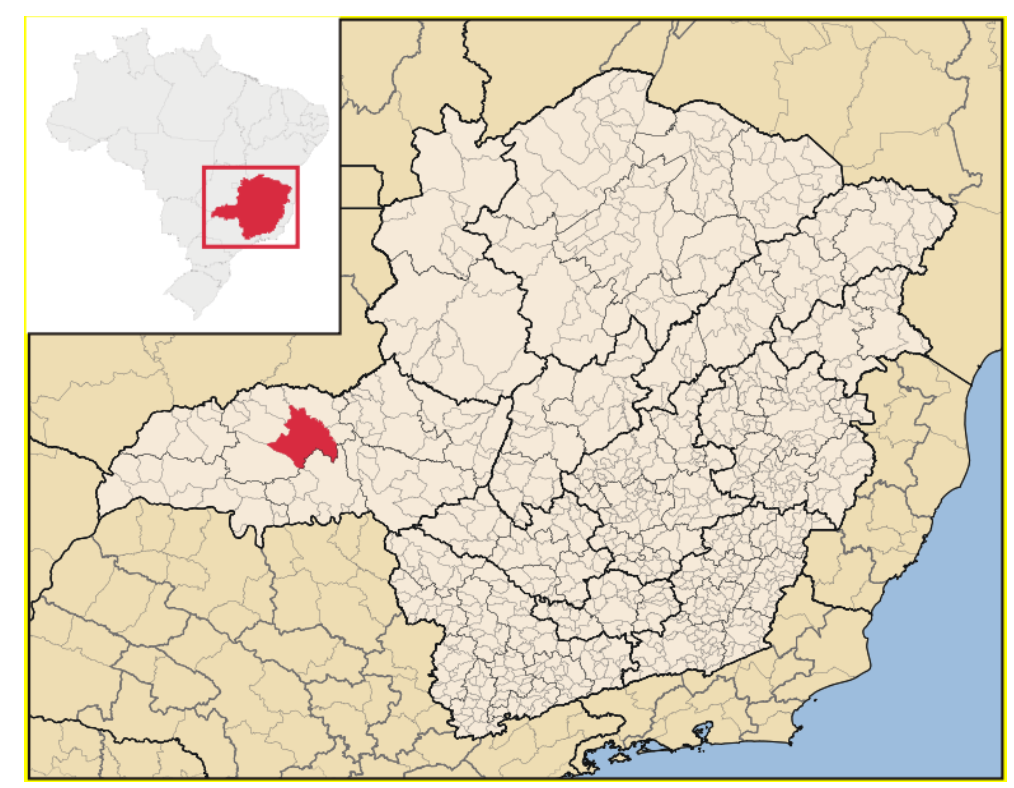

FIGURA 02 - Localização da cidade de Uberlândia no Brasil e no estado de Minas Gerais. FONTE: SEM AUTOR. Disponível em: < http:// www.ibge.br,>. Acesso em outubro 2013.

Foram elaboradas 3 plataformas de manuseio: 


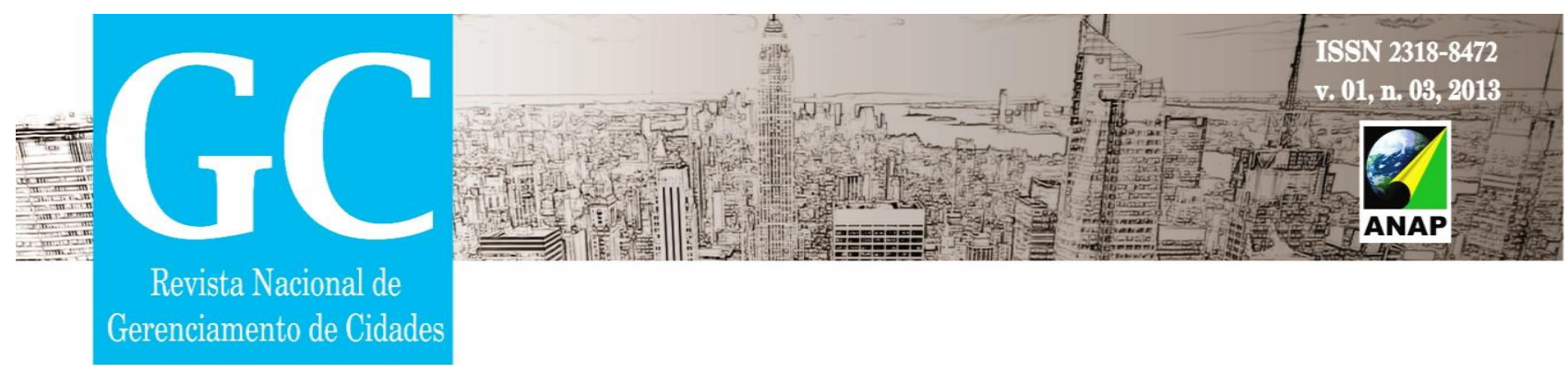

- 01 - Descrição do condomínio: É a página de apresentação do sistema, que possui o acesso ao condomínio desejado, como também o download de todos os documentos, como normas, atas de reuniões e resoluções. $O$ acesso é feito por meio de login e senha. O sistema permitiu o armazenamento de dados de forma facilitada a todos os usuários, e separados por condomínio, quadras e lotes.

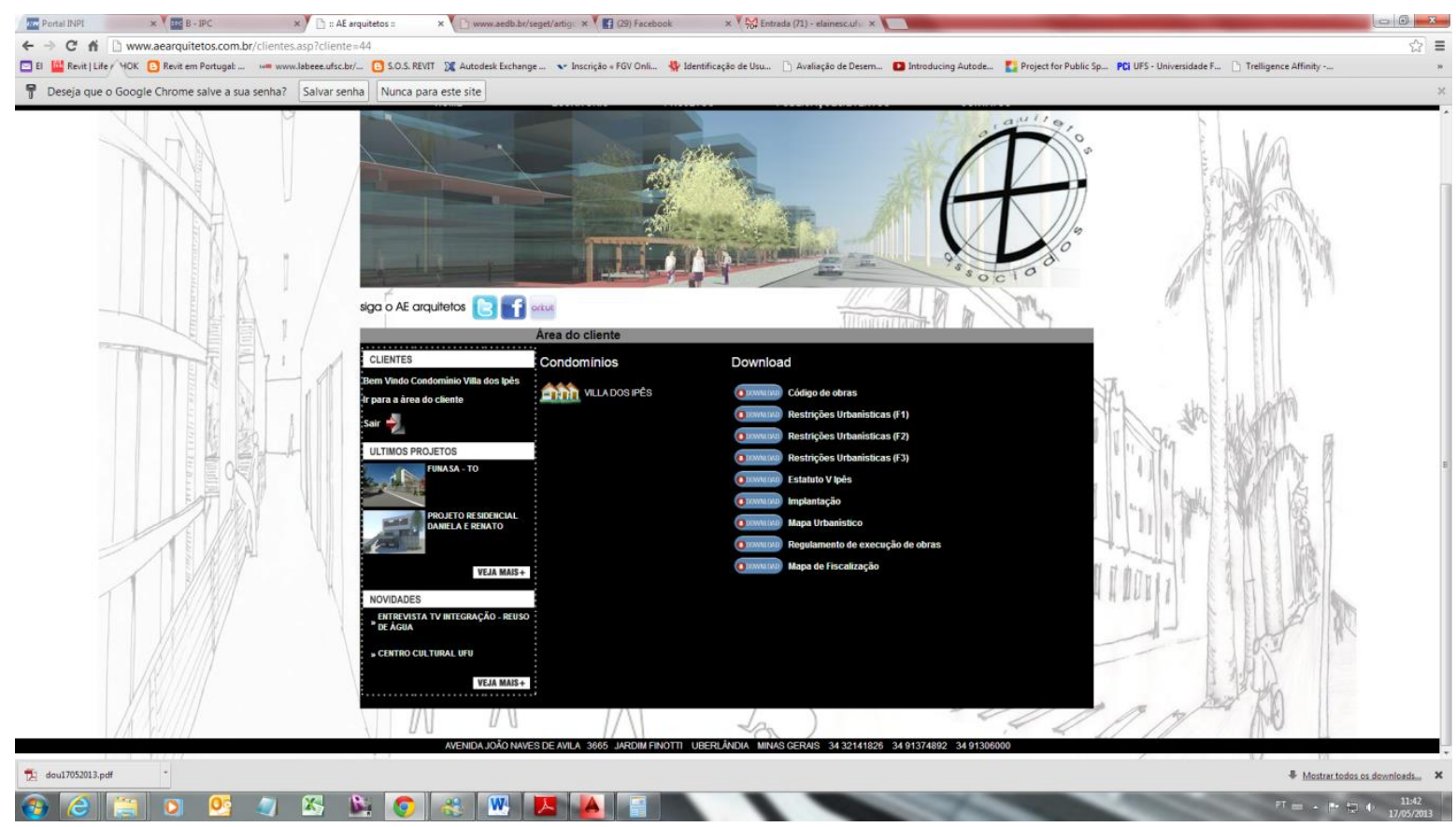

FIGURA 03 - Pagina de apresentação do sistema FONTE: Autores.

- 02 - Descrição das Quadras: É apresentado o projeto urbano completo do condomínio acessado, conforme apresentado na Figura 04, mostrando o número de quadras, localização e a situação de cada lote (vago, em construção e em aprovação, entre outros). 

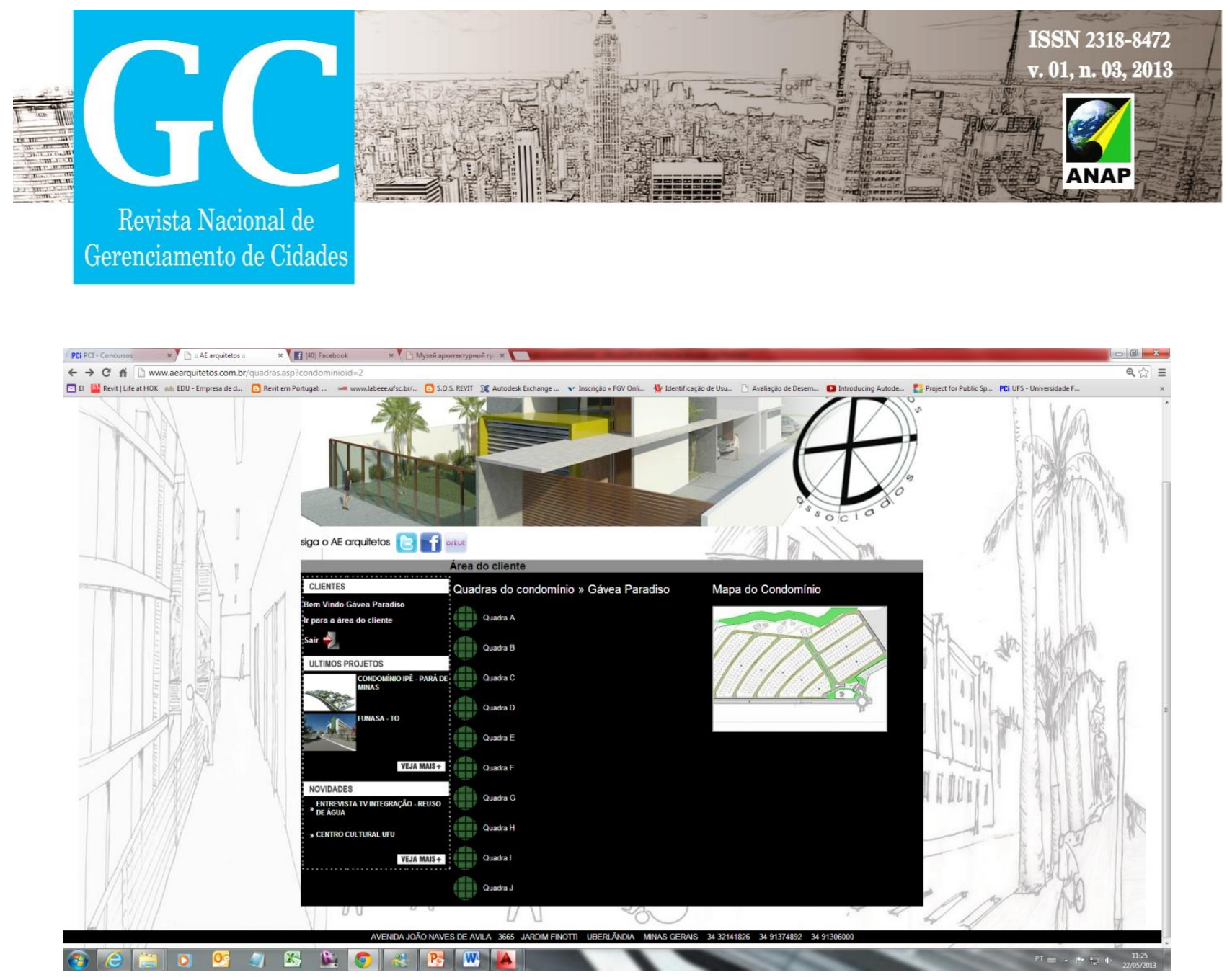

FIGURA 04 - Acesso ao mapa (projeto urbano) e as quadras de cada condomínio.

FONTE: Autores.

- 03 - Descrição dos Lotes: É apresentado o sistema dentro de cada quadra do loteamento, com a indicação do lote fiscalizado na barra superior. Neste local, são cadastradas todas as normas do condomínio e indicados os períodos de fiscalização: inicio, durante e a finalização da obra, como também são indicados os itens a serem fiscalizados e se houveram notificações ou não, assim como se ainda estão pendentes. Na cor vermelho, são indicadas notificações e inserido em forma de texto as observações realizados no local, já na cor amarelo são itens que estão aguardando soluções e em verde já solucionado, no entanto, permanecem no sistema como registro e arquivo de obra. 


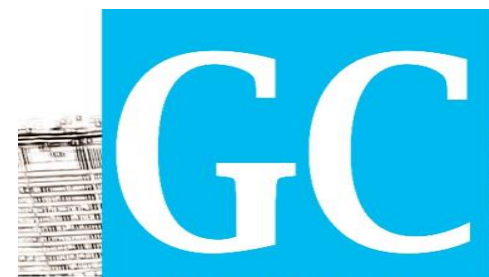

Revista Nacional de

Gerenciamento de Cidades

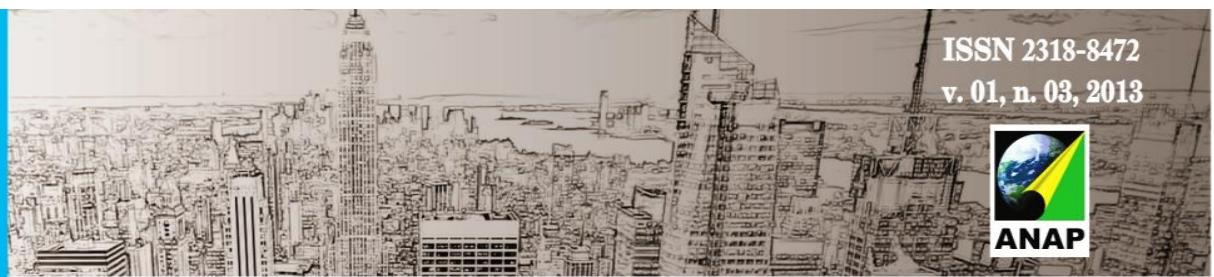
(1)

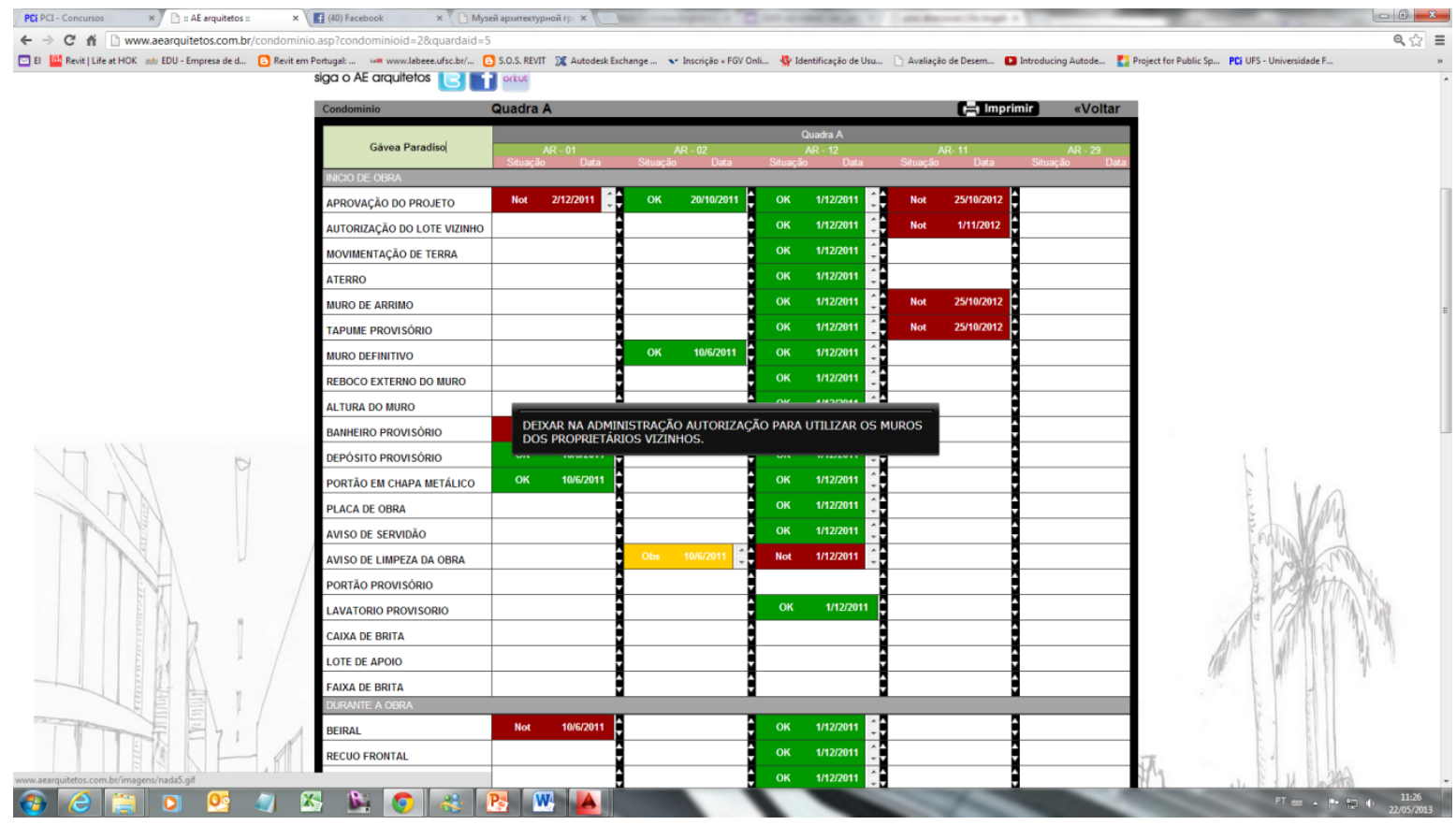

FIGURA 05 - Sistematização da fiscalização dentro de uma quadra. FONTE: Autores.

O sistema ainda permite o armazenamento das fotografias do local, como indicativos do problema verificado e armazenamento de dados para futuros questionamentos, conforme apresentando na Figura 06. 

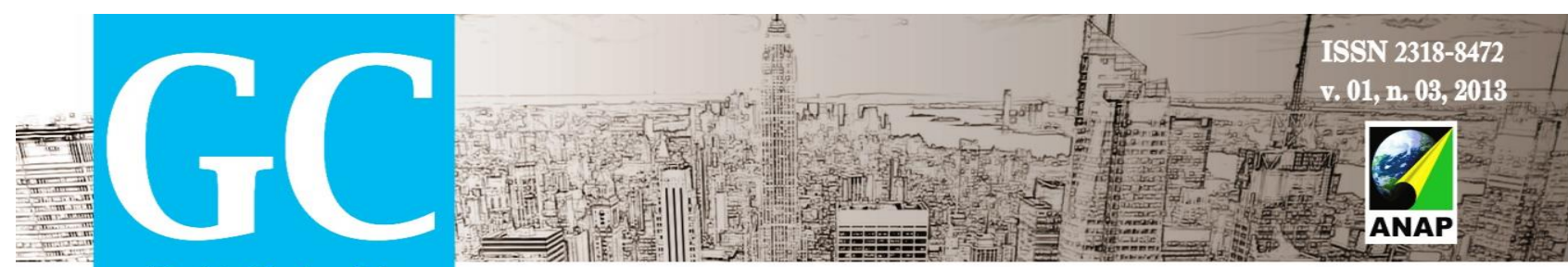

Revista Nacional de

Gerenciamento de Cidades

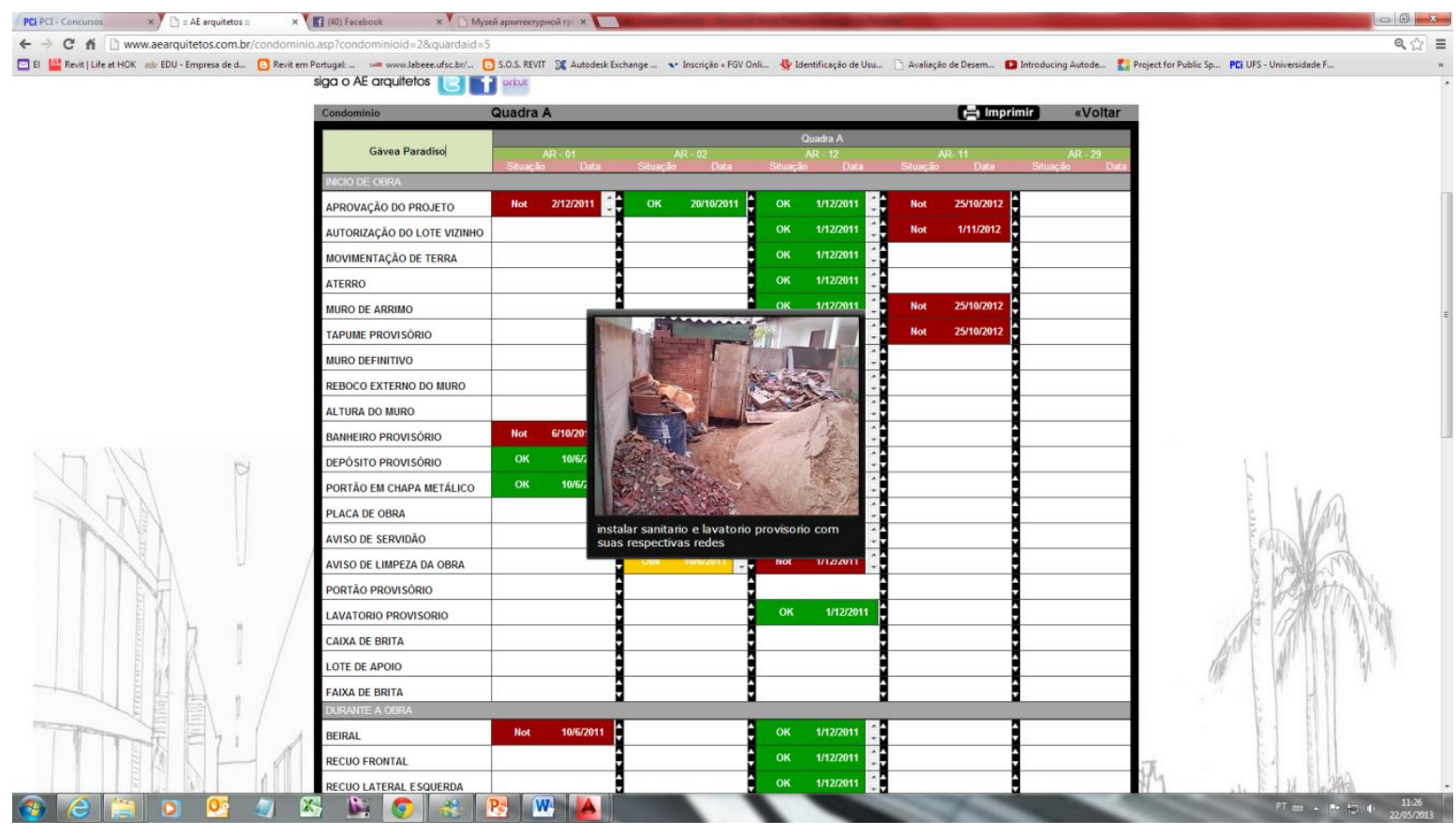

FIGURA 06 - Armazenamento de fotografias.

FONTE: Autores.

Com as informações inseridas, automaticamente a administração do condomínio, o preposto e o proprietário da obra, recebem via email, um relatório da notificação, com o prazo determinado para a solução do problema questionado.

\section{CONCLUSÕES E RECOMENDAÇÕES}

Em análise no rendimento da empresa, observou-se que o sistema proporcionou a otimização no gerenciamento e fiscalização de obras em torno de $50 \%$, em tempo e agilidade nas notificações e demais processos, além da melhoria significativa no armazenamento de dados, e em torno de $80 \%$ na comunicação entre os envolvidos (fiscal, administração e o proprietário).

Atualmente a empresa iniciou um processo de elaboração de um aplicativo para uso exclusivo em smartphones e tablets, no intuito é aumentar em torno de $80 \%$ a produção da empresa e alcançar em $100 \%$ a comunicação entre os usuários. Além de 

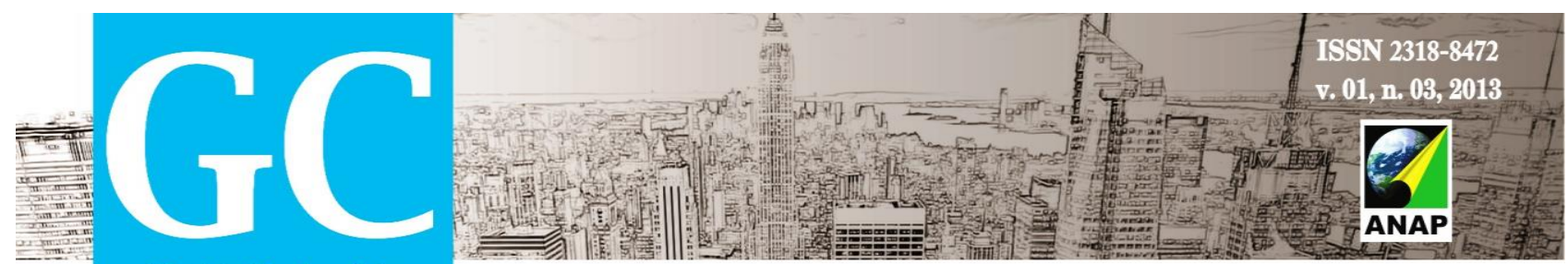

Revista Nacional de

Gerenciamento de Cidades

melhoria em todos os procedimentos de trabalho, na programação das atividades, na descrição das funções e no ambiente de trabalho.

Sabemos que implantação de novas tecnologias em empresas de prestação de serviços é um fenômeno que vem ocorrendo mais intensamente, no Brasil, desde o final da década de 70, e vão sempre provocar mudanças no ambiente social da organização e é difícil imaginar alguma inovação tecnológica que pudesse ser introduzida na empresa sem provocar algum efeito.

No entanto, não mais como uma necessidade, é sim de estabelecer agilidade e qualidade nos produtos, além da garantia no futuro das empresas. E incorporar no processo de trabalho as tecnologias que possibilitem a modernização da empresa, como forma de prestar um melhor atendimento ao cliente e possibilitar um sistema de informações, controle e gerenciamento que seja capaz de gerar menores custos, e tempo de execução.

\section{REFERÊNCIAS BIBLIOGRÁFICAS}

BECKER, D. Condomínios horizontais fechados: avaliação de desempenho interno e impacto físico espacial no espaço urbano. 2003. 308 p. Dissertação (Mestrado em Planejamento Urbano e Regional). Faculdade de Arquitetura e Urbanismo, Universidade Federal do Rio Grande do Sul, Porto Alegre.

INSTITUTO PÓLIS, CÂMARA DOS DEPUTADOS e outros. Estatuto da Cidade - Guia para implementação pelos municípios e cidadãos. Brasília: Centro de Documentação e Informação, 2001.

GONÇALVES, Jose Ernesto. Os impactos das novas tecnologias nas empresas prestadores de serviços. Revista de Administração de empresa, São Paulo, 2000. 


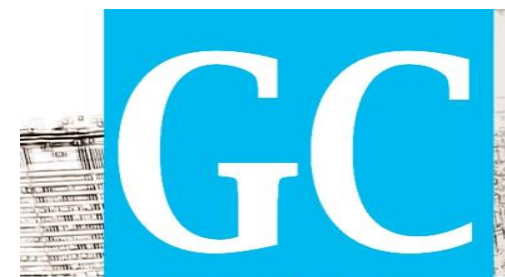

Revista Nacional de

Gerenciamento de Cidades

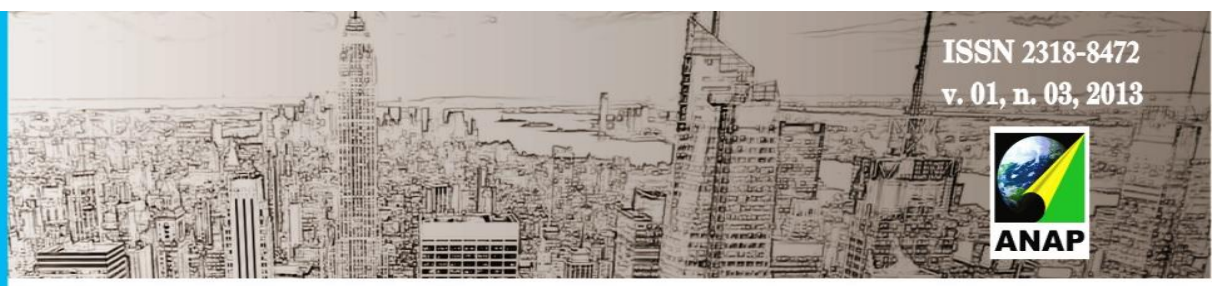

LAMAS, José M. R. G. Morfologia urbana e desenho da cidade. Lisboa: Fundação Calouste Gulbenkian, 1999.

MOURA, Rosa. Políticas públicas urbanas: ausências e impactos. In: MENDONÇA, Francisco. Impactos socioambientais urbanos. Curitiba: Ed. UFPR, 2004.

ROLNIK, Raquel. O que é cidade. Coleção Primeiro Passos - 203. São Paulo: Ed. Brasiliense, 3를. ed., 1995.

RUANO, MI. Ecourbanismo, Entornos Humanos Sostenibles: 60 Proyetos. Barcelona: Editorial

Gustavo Gili, 1999. 